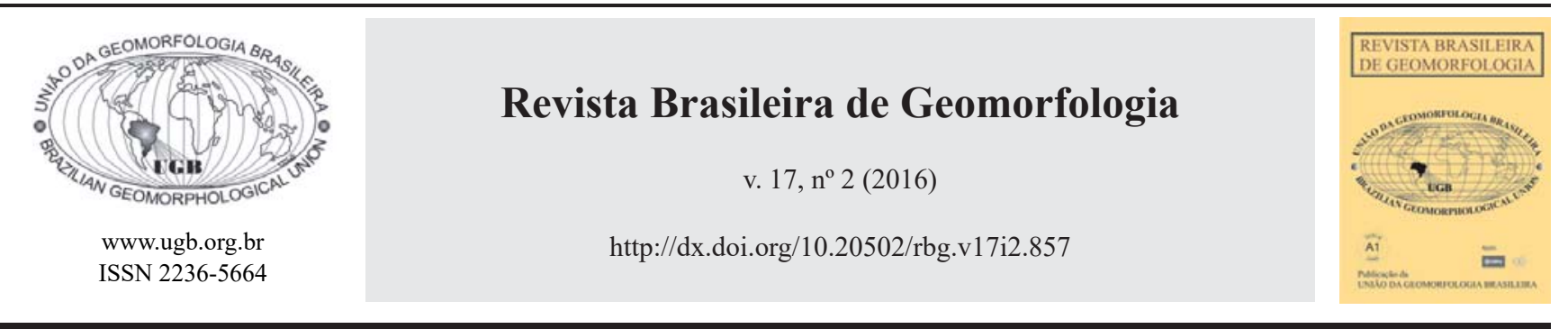

\title{
COMPARTIMENTAÇÃO DO ESTADO DO RIO GRANDE DO SUL, BRASIL, ATRAVÉS DO USO DE GEOMORPHONS OBTIDOS EM CLASSIFICAÇÃO TOPOGRÁFICA AUTOMATIZADA
}

\section{SUBDIVISION OF THE STATE RIO GRANDE DO SUL, BRAZIL, THROUGH GEOMORPHONS OBTAINED FROM USE IN AUTOMATED CLASSIFICATION SURVEYING}

\author{
Luís Eduardo de Souza Robaina \\ Departamento de Geociências, Universidade Federal de Santa Maria \\ Av. Roraima, 1000, Prédio 17, Santa Maria, Rio Grande do Sul, CEP 97105-900, Brasil \\ Email: lesrobaina@yahoo.com.br \\ Romario Trentin \\ Departamento de Geociências, Universidade Federal de Santa Maria \\ Av. Roraima, 1000, Prédio 17, Santa Maria, Rio Grande do Sul, CEP 97105-900, Brasil \\ Email: romario.trentin@gmail.com \\ François Laurent \\ Espaces et Sociétés, Université du Maine \\ Avenue Olivier Messiaen, Cedex 9, Le Mans, CEP: 72085, França \\ Email: francois.laurent@univ-lemans.fr
}

Informações sobre o Artigo

Recebido (Received):

29/02/2016

Aceito (Accepted):

25/04/2016

Palavras-chave:

Formas de relevo; Geomorphons; Compartimentação; Rio Grande do Sul.

Keywords:

Landforms; Geomorphons;

Compartimentation; Rio

Grande do Sul.

\section{Resumo:}

Trabalhos relacionados à análise de relevo são instrumentos básicos em projetos e planos de gestão. Dessa forma, o presente trabalho possui como objetivo a determinação de compartimentos de formas de relevo para o estado do Rio Grande do Sul, através do uso de geomorphons determinados em classificação topográfica automatizada. Para a definição dos geomorphons, foi utilizada o MDE obtido através dos dados SRTM (Shuttle Radar TopographyMission), processado em ambiente online. Através do agrupamento manual, a partir de interpretação de tela em SIG, definiram-se sete compartimentos de formas de relevo, sendo: Encostas com bases amplas, Encostas com topos estreitos e alongados, Encostas com vales encaixados, Encostas amplas com rebaixamentos na meia-encosta, Encostas com base ampla e topos com ressaltos, Áreas planas e Áreas planas associadas a encostas de bases amplas. Este último compartimento é o predominante no estado, com 25,95\% da área total. Ocorre, principalmente, seguindo a planície de inundação dos rios como o Ibicui, em direção a Oeste; rio Jacuí, em direção Leste, e o rio Santa Maria, ao Sul. Este elemento de relevo está associado, principalmente, à região geomorfológica da Depressão Central Gaúcha, sobre substrato de rochas sedimentares da Bacia do Paraná. O segundo maior compartimento de formas de relevo do estado é o compartimento das Encostas com bases Amplas, ocupando 
$21,52 \%$ da área total. Este compartimento ocupa a maior área no Norte do estado, formando os divisores entre as duas mais importantes bacias, do Uruguai e do Guaíba. A identificação dos elementos do relevo, denominados geomorphons, mostrou-se uma técnica bastante eficiente na delimitação de diferentes compartimentos de formas de relevo no estado do Rio Grande do Sul, com distintas e peculiares características que correspondem a unidades reconhecidas geomorfologicamente.

\begin{abstract}
:
Studies of the relief are basic tools in projects and management plans. The present work aims the compartment of landforms for the Rio Grande do Sul state through the use of geomorphons obtained from automated topographic classification. The geomorphons elements were determined used the Digital Elevation Model (DEM) obtained through the SRTM data (Shuttle Radar Topography Mission), processed online. Manual grouping from screen in GIS of the geomorphons elements were defined seven compartments of landforms, as follows: Slopes with large footslopes; Slopes with narrow and elongated tops; Slopes with enclosed valleys, Slopes with hollow; Slopes with large footslopes and tops in shoulder; Flat Areas and Flat Areas associated with large footslopes. This latest compartment is predominant, with $25.95 \%$ of the total area. It occurs mainly following the flooding plain of the rivers as Ibicui, in the West, Jacuí in East and the Santa Maria to the South. They are the main relief elements of the geomorphological region Central Depression Gaúcha on sedimentary rocks in the Paraná Basin. The second more important compartment is the of the Slopes with large footslopes, occupying $21.52 \%$ of the total area. This compartment occupies the largest area in the state's northern region, forming the dividers between Uruguay basin and Guaiba basin. The identification of relief elements, called geomorphons, proved to be a very effective technique in the delimitation of different landforms compartments in the Rio Grande do Sul state, with distinct characteristics that correspond to units recognized geomorphologically.
\end{abstract}

\section{Introdução}

Os estudos do relevo e da rede de drenagem são instrumentos básicos para planos de gestão, que visem à utilização racional do meio ambiente e à compreensão dos processos naturais atuantes. Estas análises são largamente utilizadas na obtenção de informações sobre a dinâmica da paisagem, sendo de grande relevância nos estudos geomorfológicos.

Alguns dos primeiros estudos que analisaram e classificaram o relevo a partir de parâmetros morfométricos (baseando-se no comportamento de fluxos superficiais em vertentes) foram desenvolvidos por Troeh (1965) e Huggett(1975). Troeh (1965) apresentou a classificação de quatro principais tipos de vertentes: as coletoras de água, com plano de curvatura convergente e as distribuidoras de água, com plano de curvatura divergente. Sob o aspecto do perfil de curvatura, as vertentes convexas são as que facilitam o desenvolvimento do rastejamento e as côncavas, as que favorecem a lavagem pela água das chuvas. Huggett (1975) estabeleceu a combinação de formas de vertentes relacionando a curvatura vista em perfil e em plano, propondo nove padrões de vertentes. Nessas, os fluxos da água e a sua distribuição promovem diferenças na atuação dos processos superficiais.

A partir dos Sistemas de Informações Geográficas (SIG), a obtenção dos atributos do relevo passou a ser um procedimento de mais fácil acesso, permitindo classificar e descrever de forma quantitativa as formas da superfície da Terra por meio de equações aplicadas a modelos numéricos de representação altimétrica (MUÑOZ, 2009).

Os métodos de classificação atuais possibilitaram a subdivisão das formas em elementos do relevo, que são um conjunto de parcelas de um tipo de relevo relativamente homogêneo em relação à forma (curvaturas de perfil e de plano), à inclinação (declividade), à orientação ou à exposição (aspecto ou radiação solar) e ao posicionamento na paisagem (MACMILLAN e SHARY, 2009).

Wood (1996) propõe um método que extrai e classifica seis Formas de Terreno (FTs): Plane, Channel, Ridge, Pass, Peak e Pit. O método considera uma combinação específica dos pares de curvaturas Longitudinal/Transversal e Mínima/Máxima a depender da declividade da região a ser classificada (SENA-SOUZA et al., 2015).

Schmidt e Hewitt (2004) desenvolveram um 
procedimento que permite obter diferentes ETs (Elementos do Terreno), utilizando como critério a posição da paisagem, dividindo-a em áreas planas e em áreas dissecadas a partir da curvatura tangencial, vertical, mínima e máxima. Dragut e Blaschke (2006) optaram por segmentar os objetos dos Modelos de Elevação relativamente homogêneos em vários níveis geomorfológicos, utilizando curvatura de plano e curvatura vertical (VASCONCELOS et al., 2012).

Iwahashi \& Pike (2007) apresentam um método de classificação topográfica automatizada, sem supervisão, com base em três variáveis morfométricas: declividades, convexidade das encostas e textura superficial.

Recentemente, Jasiewicz \& Stepinski(2013) estabeleceram uma classificação de elementos do relevo, usando ferramentas de visão computacional ao invés de ferramentas da geometria diferencial. Os autores fizeram uma analogia entre a classificação textural de uma imagem, com base no arranjo espacial de tons de cinza, comparando-a com a distribuição especificada dos valores de elevação de um MDE de uma determinada região, com arranjo espacial de elevação. Baseando-se nesta analogia, modificaram ferramentas utilizadas na classificação textural, aplicando-as na análise de formas de relevo. Utilizaram o conceito de "Local Ternary Patterns" (LTP) (LIAO, 2010) para identificar elementos do relevo, denominados de geomorphons por analogia ao textons (JULESZ, 1981). Textons referem-se a micro-estruturas fundamentais em uma imagem e, assim, constituem os elementos básicos de percepção visual (JULESZ, 1984). Analogamente, geomorphons são micro-estruturas fundamentais do relevo.

Dessa forma, podem ser elaborados 'mapas geomorfometricos' a partir de algoritmos, permitindo, através de técnicas computacionais, classificar e mapear elementos das formas de relevo. Cada um desses elementos pode ser expresso por um número de diferentes geomorphons.

Jasiewicz \& Stepinski (2013) demonstram como gerar um mapa com os 10 mais comuns elementos de formas de relevo designadamente: áreas planas (flat), pico (peak), crista(ridge), ressaltos (shoulder), crista secundária (spur), encosta (slope), escavado (hollow), base de encosta (footslope), vales (valley), e fosso(pit)).

Com relação aos trabalhos de compartimentação realizados no estado do Rio Grande do Sul, pode-se destacar os trabalhos de Rambo (1956), que, em seu livro "Fisionomia do Rio Grande do Sul", elaborou uma caracterização, por regiões, do estado, onde descreve aspectos geográficos, formação geo-histórica, geologia, vegetação, paisagem regional e significação da antropogeografia.

Além desse, estudos das características fisiográficas do estado do Rio Grande do Sul foram apresentados por Caldas (1938) e Nogueira (1948). Caldas dividiu o estado em zona alta e zona baixa. A zona alta foi subdividida nas Planuras de São Francisco de Paula, Vacaria, Cruz Alta e Missões; a zona baixa foi subdividida em Região do Maciço, da Depressão Transversal e Litorânea. Nogueira dividiu em quatro regiões que, até hoje, são muito utilizadas: Litoral, Escudo Sul-Riograndense, Sedimentos Gonduânicos e Planalto.

Em 1954, Chebataroff apresentou uma nova divisão fisiográfica do Uruguai e do Rio Grande do Sul, acrescentando duas novas regiões e subdividindo em sub-regiões. O autor apresenta, pela primeira vez, a região denominada Cuesta basáltica de Haedo na região oeste do estado. Usando como base este trabalho, em 1970, Müller Filho propôs a divisão do estado em: Planalto, Cuesta de Haedo, Depressão Central, Escudo e Planície Costeira.

Carraro et al. 1974 publicaram o mapa geomorfológico do estado com quatro províncias: Escudo Sul Riograndense, Depressão Periférica, Planalto e Planície Costeira.

Moreira e Lima (1977) apresentam uma divisão utilizando uma proposta de taxonomia e determinando regiões morfoestruturais, unidades e subunidades estruturais.

Um importante trabalho sobre a compartimentação do estado foi realizado pelo Projeto Radam Brasil incorporado pelo IBGE, em 1986, que utiliza, como base, os diversos trabalhos desenvolvidos e faz uma divisão em Domínios Morfoestruturais, Regiões Geomorfológicas e Unidades Geomorfológicas. Nesse trabalho, o estado foi dividido em seis regiões geomorfológicas: o Planalto das Araucárias, localizado na porção nordeste, onde se localizam as maiores altitudes; o Planalto das Missões ao norte e o Planalto da Campanha no oeste, onde o relevo apresenta um mergulho em direção ao rio Uruguai; na parte centro-sudoeste do estado, seguindo os canais fluviais do rio Jacuí, Ibicui e Santa Maria, ocorre a Depressão Central Gaúcha; na região denominada Planalto Sul Riograndense, centro-sul do estado, ocorrem 
as rochas do maciço cristalino antigo; ao longo da costa do Atlântico, a região da Planície Costeira.

Neste trabalho, estabeleceu-se uma compartimentação do estado do Rio Grande do Sul, localizado no extremo sul do Brasil, utilizando e adaptando a proposta apresentada por Jasiewicz \& Stepinski (2013) com base no predomínio e na relação dos elementos de relevo definidos como geomorphons(Figura 1).

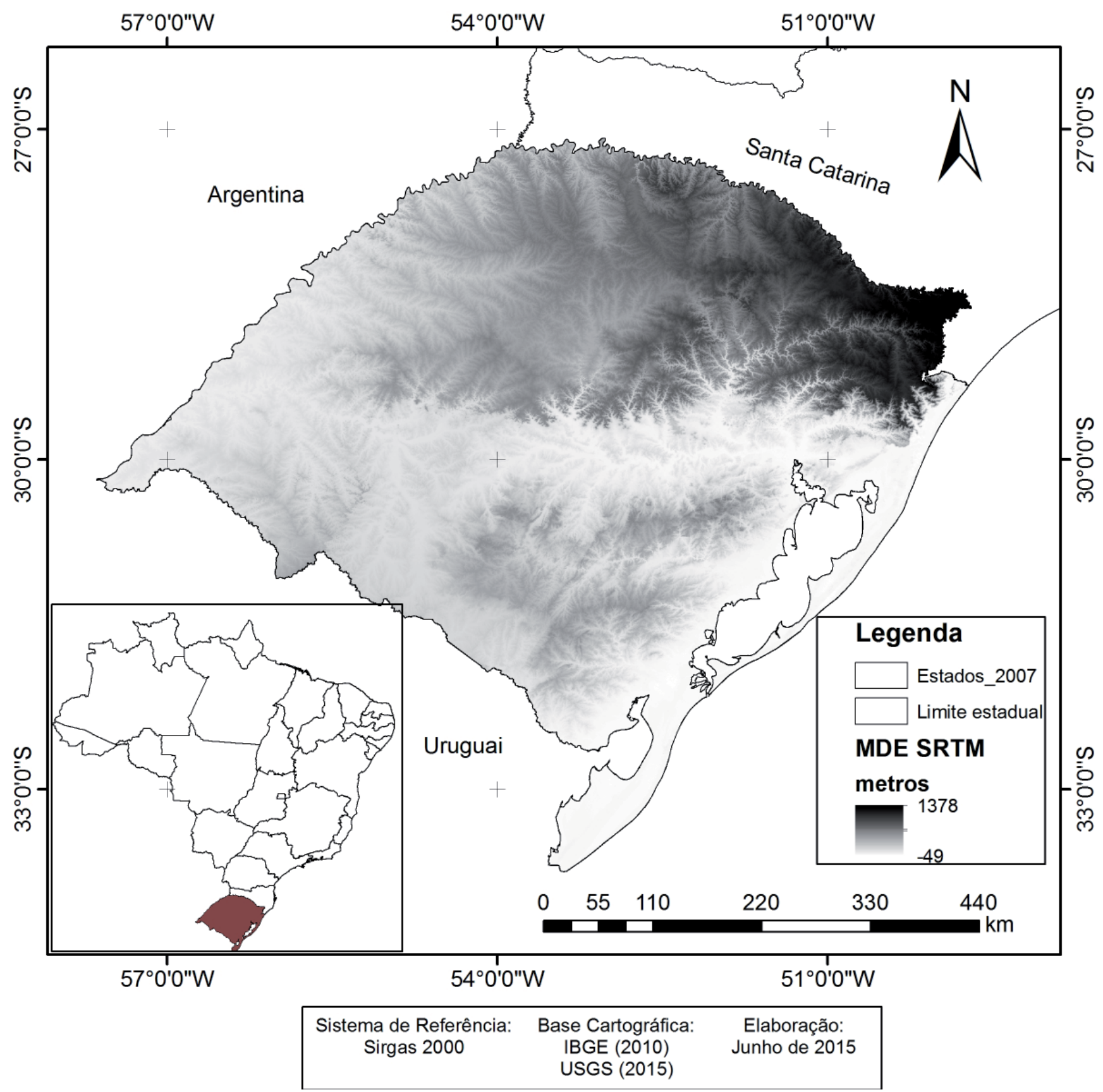

Figura 1 - Mapa de localização do estado do Rio Grande do Sul, mostrando as variações altimétricas

\section{Metodologia}

Para o desenvolvimento do presente trabalho, utilizaram-se alguns aplicativos e bases cartográficas que cabem ser apresentadas antes da segmentação dos procedimentos metodológicos e das rotinas específicas de desenvolvimento das etapas do presente trabalho.

Destaca-se, inicialmente, o aplicativo ArcGIS ${ }^{\circledR}$, o qual disponibilizou as ferramentas para a criação, análise e ponderação das bases cartográficas utilizadas ao longo do trabalho. 
As bases cartográficas utilizadas neste trabalho foram constituídas pelo limite político administrativo do estado do Rio Grande do Sul, disponibilizado pelo Instituto Brasileiro de Geografia e Estatística (IBGE, 2010), utilizado para definir os limites da área de interesse da pesquisa, e o Modelo Digital de Elevação, originado da missão Shuttle Radar Topography Mission (SRTM), disponibilizado pelo United States Geological Survey (USGS), com resolução espacial de 3 arc-second (90 metros).

A metodologia aplicada na definição dos geomorphons deste trabalho é baseada na proposta de Jasiewicz $\&$ Stepinski (2013), que analisa a similaridade textural do MDE, considerando a variação de níveis de cinza entre uma célula central e as células vizinhas, considerando que se a célula central for maior, assume o valor de " 1 ", se é menor "-1"e se é igual, "0". Esta informação é transferida para valores de elevação do terreno de maior, menor ou igual (Figura 2).
Conforme Jasiewicz e Stepinski, (2013), para caracterizar a superfície do relevo não basta a diferença de altura, sendo necessária a distância e o ângulo de direção dos pontos vizinhos em relação à célula central (ângulos zenith e nadir). Para esse cálculo, perfis são traçados para as principais direções a partir da célula central "lookupdistance" (L)., extraídos do Modelo Digital de Elevação.

Um ângulo de elevação é um ângulo entre o plano horizontal e a linha que liga a célula central com o ponto no perfil. Em uma elevação com ângulo negativo, o ponto no perfil é mais baixo que o central. Para cada perfil, é calculado o ângulo de elevação " $\mathrm{D}_{\mathrm{L}}$," com " $\mathrm{D}$ " e "L" demonstrando a dependência da direção (D) e da distância (L).

O ângulo zenith do perfil é definido por " $\mathrm{D} \phi \mathrm{L}=90^{\circ}$ $D \beta L$ ", onde "D $\beta L$ " é o ângulo máximo de elevação " $\mathrm{S}$ L". O ângulo nadir do perfil é definido como " $\mathrm{D} \psi \mathrm{L}=$ $90^{\circ}-\mathrm{D} \delta \mathrm{L}$ ", onde "D $\delta \mathrm{L}$ " é o ângulo mínimo de elevação

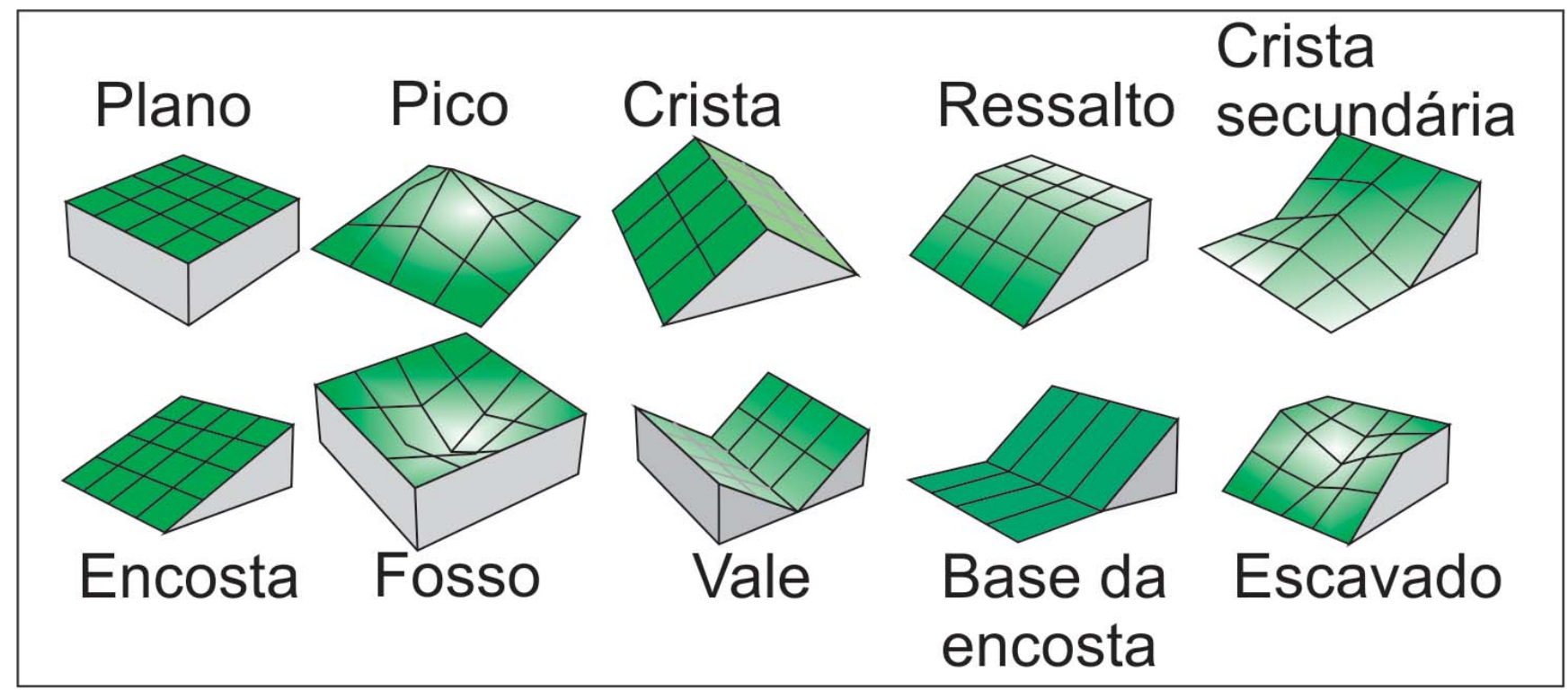

Figura 2 - Principais Geomorphons reconhecidos na análise do relevo. Modificado de Jasiewicz\&Stepinski (2013). Org.: os autores

“ $\mathrm{S}_{\mathrm{L}}$ ”. Assim, o ângulo Zenith é um ângulo entre o Zenithe a "line-of-sight", e o ângulo nadir é um ângulo entre o nadir e uma hipotética "line-of-sight", que resulta da reflexão do perfil da elevação em relação ao plano horizontal. Ambos são positivos e definidos entre $0^{\circ}$ a $180^{\circ}$.

Para a realização do processamento do MDE e a geração dos geomorphons, utilizou-se a aplicação online, disponibilizada no endereço eletrônico $<<$ http://sil. uc.edu/geom/app $>>$. O código da aplicação também está disponível para baixar em http://sil.uc.edu/, podendo ser implementada no ambiente do software SAGA.

A aplicação exige um conjunto de dados raster e dois valores escalares, livres, como parâmetros. O arquivo de entrada para a varredura é uma MDE. Os dois parâmetros livres são lookup "L" (distância em metros ou célula unidades) e thresholdt (nivelamento em graus). Para os parâmetros livres, aplicou-se valor de "L" igual a 20 pixels (1800 metros) e graus " $t$ " igual a $2^{\circ}$. 
As escalas espaciais dessas paisagens variadas são identificáveis na figura 3 , com padrões diferentes de cores que representam elementos do relevo.

Após o processamento dos MDEs em ambiente online definindo as 10 classes de geomorphons em ambiente SIG, utilizou-se a interpretação visual de tela para estabelecer os agrupamentos predominantes no estado do Rio Grande do Sul, o que propiciou a determinação de sete Compartimentos de formas de relevo.

\section{Resultados}

A distribuição espacial dos elementos de relevo (geomorphons), classificados em 10 unidades, conforme resultado do processamento digital do MDE, está apre- sentada na figura 3. Observa-se, neste mapa, o grande percentual de elementos de Áreas planas, Encostas e Vales. As áreas com elementos de Cristas e Escavados também são significativas e, associadas com as três primeiras, permitem definir compartimentos.

Os elementos de relevo (geomorphons) foram agrupados em sete compartimentos de A a G, como pode ser visto no mapa da figura 4 . O compartimento com maior ocorrência é o D, que representa $25,95 \%$ da área total, seguido dos compartimentos $\mathrm{A}$, com $21,52 \%$; do compartimento E, com $19.39 \%$; do compartimento F, com 13,24\%; do compartimento B, com $11,20 \%$. As menores áreas de ocorrência estão no compartimento $\mathrm{G}$, com $5,02 \%$ e no compartimento $\mathrm{C}$, com 3,68 , como pode ser visualizado na figura 5 .

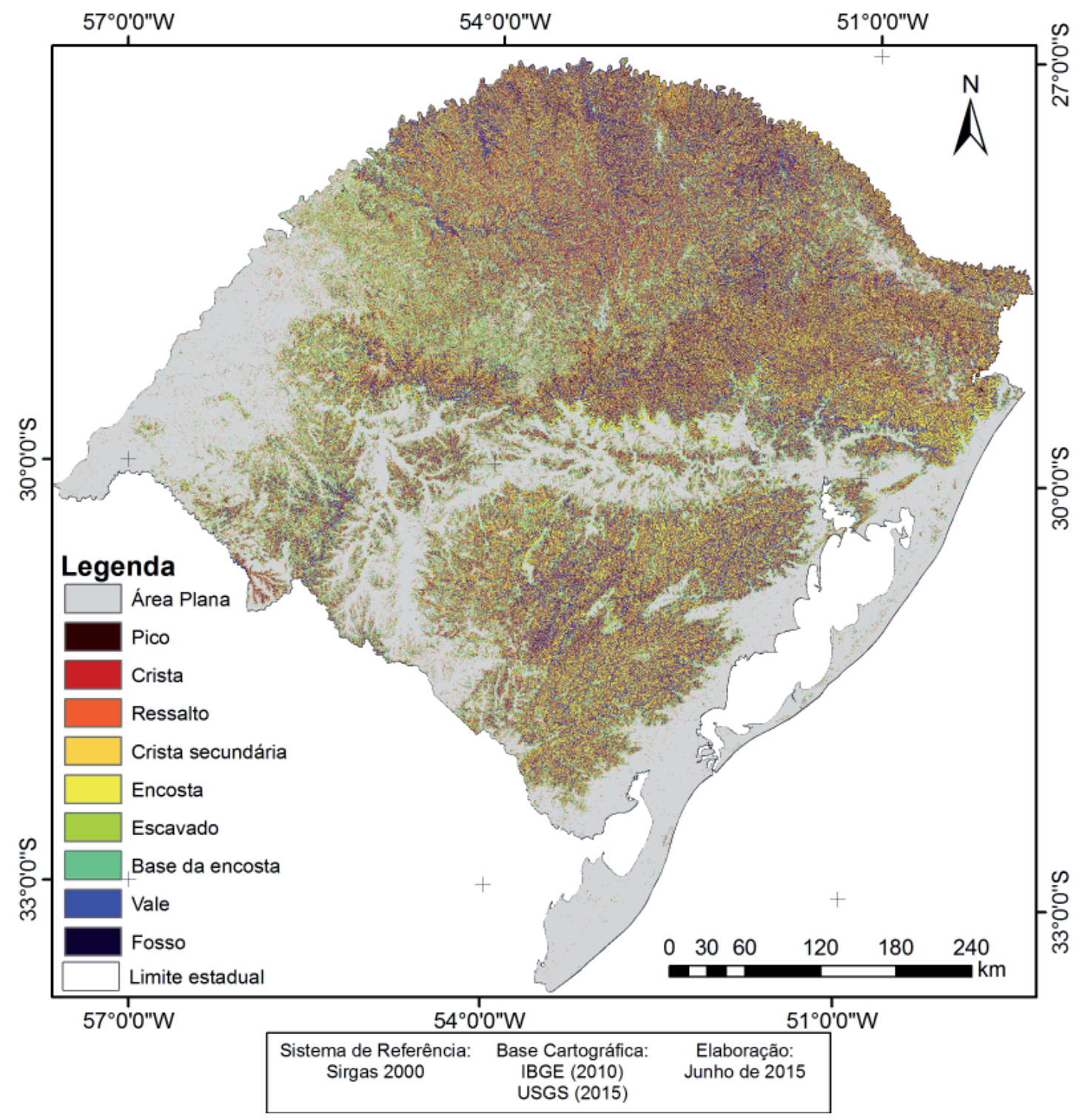

Figura 3 - Distribuição espacial dos geomorphons no estado do Rio Grande do Sul. Org.: os autores 
A figura 6 apresenta a porcentagem dos elementos de relevo (geomorphons) presentes em cada Compar- timento definidos para o estado do Rio Grande do Sul, que é discutido na apresentação de cada compartimento.

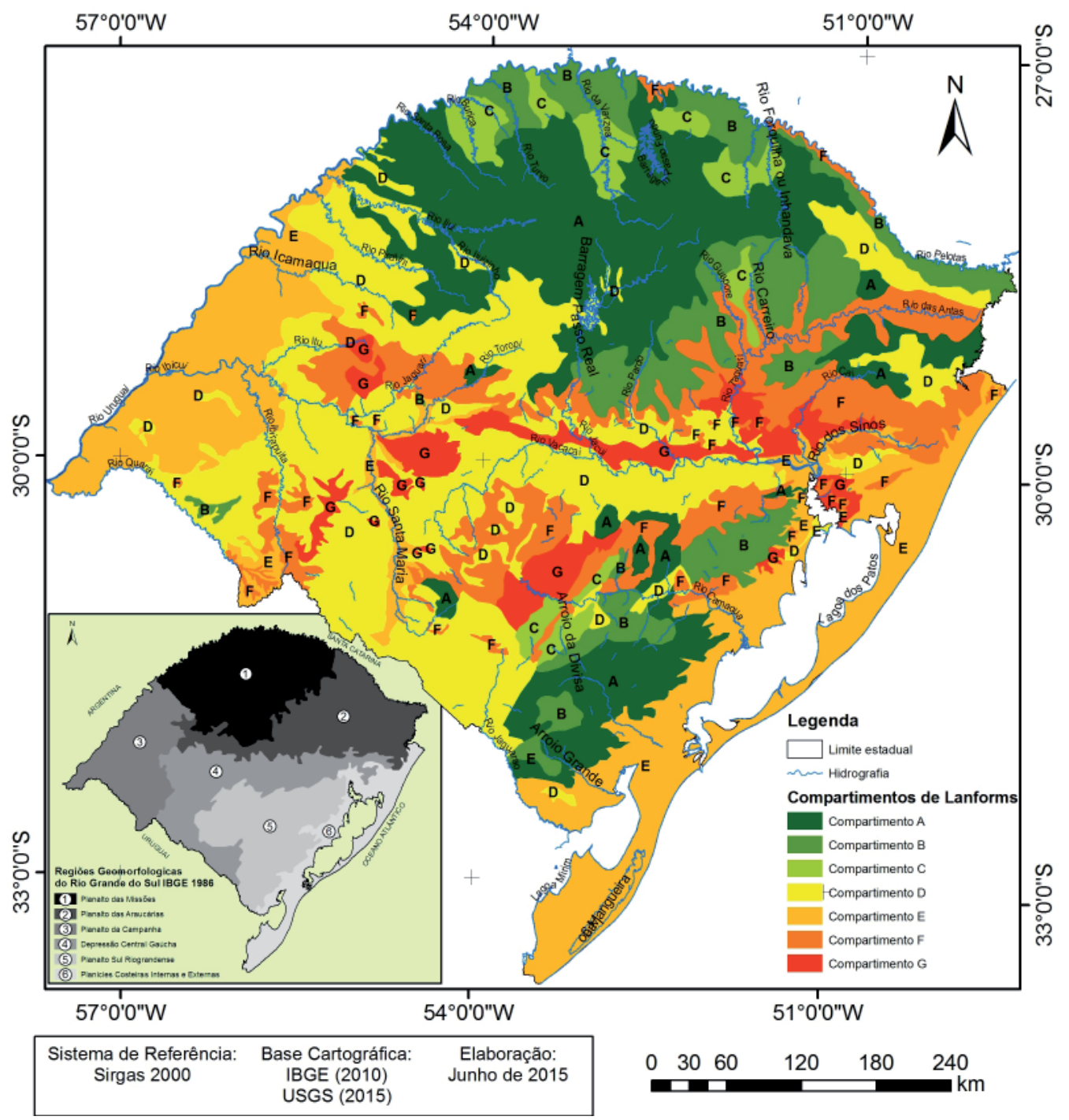

Figura 4 - Compartimentos de formas de relevo do estado do Rio Grande do Sul. Org.: os autores

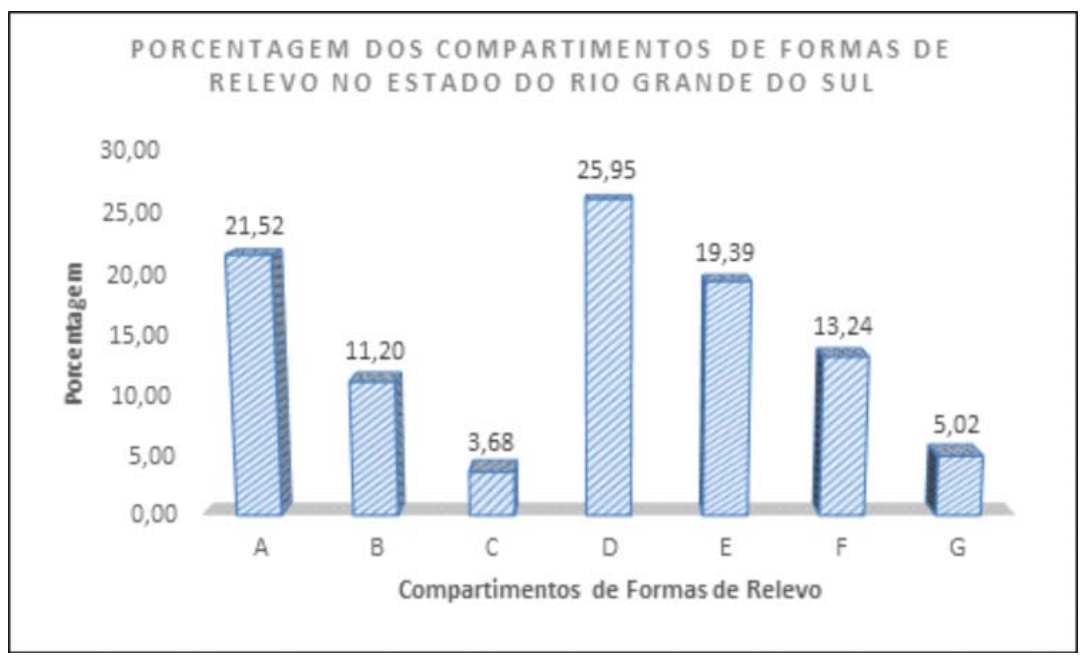

Figura 5 - Distribuição das porcentagens da área ocupada pelos compartimentos no estado do RS. Org.: os autores 


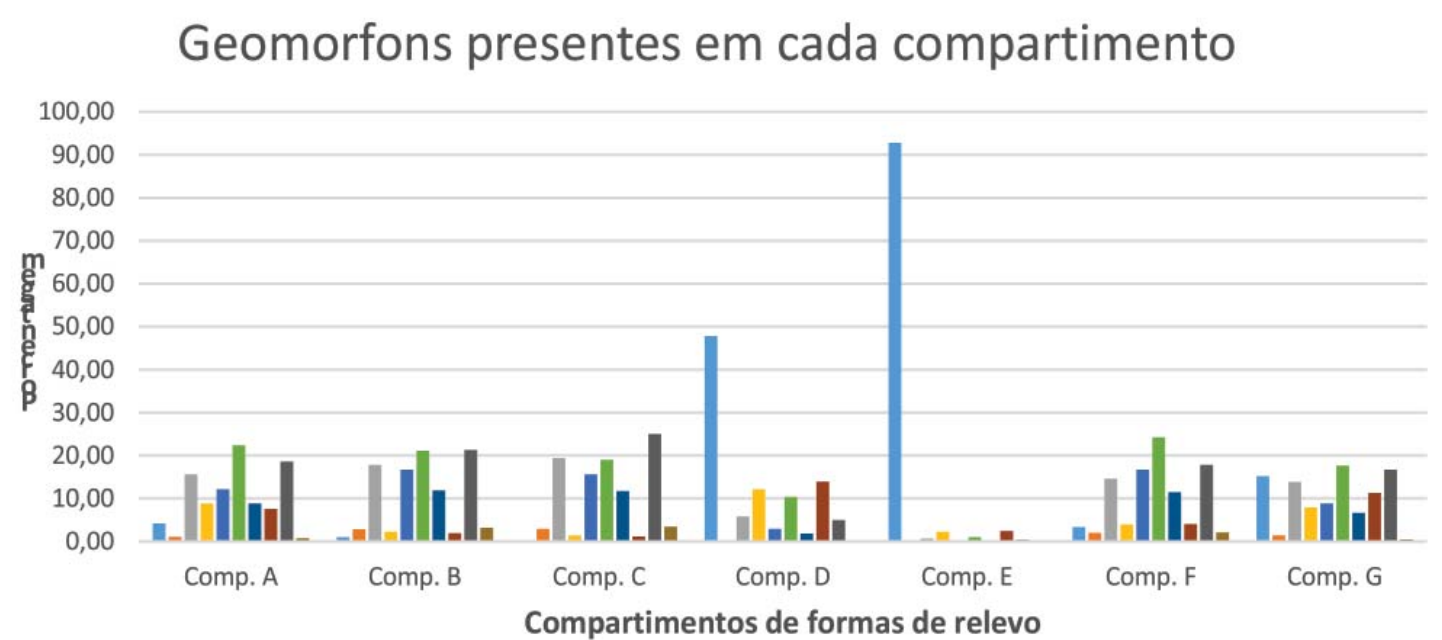

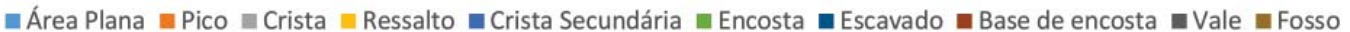

Figura 6 - Porcentagem dos Geomorphons presentes em cada Compartimento de formas de relevo do estado do Rio Grande do Sul. Org.: os autores

\section{Compartimento A- Encostas com bases Amplas}

O compartimento A é caracterizado por encostas com bases amplas, com topos estreitos e alongados que se associam a ressaltos e cristas laterais. A drenagem desenvolve-se, predominantemente, em elementos de relevo de Vales, ocorrendo associados elementos de relevo que marcam rebaixamentos na meia encosta.

Este compartimento ocupa a maior área no Norte do estado, formando os divisores entre as duas mais importantes bacias do rio Uruguai e a do rio Guaíba.

$\mathrm{Na}$ bacia do rio Uruguai, este compartimento forma as áreas da bacia do rio Ijuí, o alto curso das bacias dos rios Turvo, Santa Rosa, Santo Cristo, Várzea e Passo Fundo e alto e médio curso das bacias dos rios Apuaé e Inhanadava. Constituem grande parte do que é definido como região do Planalto das Missões e parte do Planalto das Araucárias (IBGE,1986). Neste compartimento, forma um relevo de colinas sobre um substrato de basaltos melanocráticos finos, ocorrem as principais jazidas de ametista do estado, variando nas porções de base para basaltos melanocráticos com frequentes intercalações de arenito (WILDNER et al., 2006), na porção centro-sul deste compartimento.

Na bacia do rio Guaíba, este compartimento está representado no Alto rio Jacuí e rio Pardo e no alto curso do rio Taquari-Antas, que constituem o Planalto das Araucárias.

Além destas áreas, ao Sul do estado, formam uma área alongada em direção NE-SW associada à região geomorfológica do Planalto sul rio-grandense ou Escudo Sul rio-grandense (IBGE,1986), mais especificamente, na área de morros e colinas granito-gnaisse do Cinturão Dom Feliciano (WILDNERet al., op. cit.).

\section{Compartimento B- Encostas com topos estreitos e alongados}

Este compartimento B é semelhante ao anterior, sendo formado por amplas encostas com topos estreitos e alongados. As diferenças estão relacionadas às maiores ocorrências de elementos de picos no topo da encosta e rebaixamentos e cavidades na meia-encosta. Além disso, os elementos que formam a base das encostas são pouco significativos, provavelmente, devido ao relevo ser mais movimentado.

O compartimento B ocorre em uma faixa a partir do extremo Norte até as bordas lestes do estado, ocupando o baixo curso dos rios Turvo, Santa Rosa, Santo Cristo, Várzea e PassoFundo, Apuaé e Inhanadava, junto ao rio Uruguai no Planalto das Missões.

No Planalto das Araucárias, este compartimento representa uma grande área no extremo NE, junto ao rio Uruguai e Pelotas, e amplas áreas na bacia do Guaíba, no alto e médio curso do rio Taquari-Antas, Pardo e Alto Jacuí, onde formam-se colinas talhadas em rochas do tipo vulcânicas básicas, melanocráticos, nos derrames de base e riodacitos a riolitos, nos superiores (WILDNER et al., 2006). 
O compartimento B também ocorre no CentroSul do estado, no Escudo SulRiograndense associado ao Cinturão Dom Feliciano, compostos por granitos e gnaisses. Forma, no município de Porto Alegre, as elevações ao longo do Lago Guaíba.

\section{Compartimento C- Encostas com vales encaixados}

O compartimento $\mathrm{C}$ foi definido como o de relevo mais movimentado. Apresenta um conjunto de formas semelhantes ao compartimento B, entretanto, os elementos de relevo definidos como vales são mais significativos.

Este compartimento encontra-se no médio curso dos rios que formam a bacia do Uruguai, como os rios Turvo, Santa Rosa, Santo Cristo, Várze e PassoFundo, associado ao Planalto das Missões, sobre rochas vulcânicas básicas de base e em derrames superiores formados por rochas ácidas com pórfiros (WILDNER et al., 2006).

Além dessas áreas, ocorre em áreas na bacia do rio Taquari-Antas, associado ao Planalto das Araucárias com rochas vulcânicas ácidas.

$\mathrm{Na}$ porção Centro-Sul do estado, ocorre como faixas alongadas para NE, no Escudo SulRiograndense formando a porção Sul do Cinturão Tijucas, constituído por rochas metamórficas.

\section{Compartimento D- Áreas Planas associados a encostas de bases amplas}

Este compartimento é representado por formas planas associadas a elevações isoladas, caracterizadas por encostas com bases amplas e, por vezes, ressaltos entre o meio e o topo da encosta.

É um compartimento que ocorre na região NW e S-SW do estado, formando uma área de transição com relevos mais movimentados, no médio e baixo curso do rio Piratini e no baixo curso da bacia do rio Ijuí e a bacia do rio Ibirapuitã. Associa-se à região geomorfológica do Planalto da Campanha (IBGE, 1986), formado por rochas vulcânicas intermediárias, tais como andesito a andesito-basalto.

O compartimento ocorre seguindo a planície de inudação dos rios Ibicui e Jacuí, na porção central do estado, além dos rios Santa Maria e Jaguarão, no Sul. Constitui os principais elementos de relevo da região geomorfológica Depressão Central Gaúcha (IBGE,1986), sobre substrato de rochas sedimentares da Bacia do Paraná.

\section{Compartimento E- Áreas Planas}

Este compartimento é caracterizado pelas formas planas, sendo que, no oeste do estado, encontra-se associado ao baixo curso de rios afluentes do rio Uruguai, tais como o rio Quaraí; o rio Ibicui, os rios Butuí-Icamaquã. Junto a foz, associa-se aos rios Uruguai e Piratini. Corresponde a uma ampla área da região geomorfológica do Planalto da Campanha, composto por rochas vulcânicas intermediárias, que variam de andesitos a andesitos-basaltos (MARTINS et al. 2011).

O compartimento E encontra-se, também, na região costeira, junto a Laguna dos Patos, lago Guaíba e Lagoa Mirim, formando o relevo da região da Planície Costeira do estado, modelada por sucessivos eventos de subida e descida do nível do mar, devido a de alterações climáticas, no Quaternário.

Além dessas áreas, está representado na faixa de terras ao longo do rio Santa Maria até a sua confluência com o rio Ibicui, associando-se ao compartimento D, na região da Depressão Central.

\section{Compartimento F- Encostas amplas com rebaixamentos na meia-encosta}

Os elementos formados por amplas encostas são a mais representativa neste compartimento. Diferencia-se do compartimento A, pela maior ocorrência de ressalto e elevações secundárias, maior ocorrência de formas de rebaixamentos e cavidades e menor representatividade dos elementos de relevo denominados base de encosta.

A principal diferença em relação aos compartimentos B e C são as encostas e as bases mais amplas, enquanto que, no topo das encostas, há relativamente maior ocorrência de ressaltos.

Este compartimento ocupa áreas nas cabeceiras do rio Quaraí e amplas áreas do alto curso do rio Ibirapuitã, na região do Planalto da Campanha, com rochas vulcânicas intermediárias, compostas por andesitos.

Elementos que representam este compartimento ocorrem em uma pequena área semi-circular, na divisa da bacia do rio Quaraí, denominada Cerro do Jarau. Essa forma tem sido trabalhada, na literatura geológica, 
como um astroblema(CRÓSTA \& LOURENÇO, 2008).

Este compartimento forma uma faixa Oeste-Leste a partir do médio curso do rio Ibicui, em sua margem direita, dividindo regiões representadas pelo Planalto da Campanha e Depressão Central constituído por vulcânicas básicas intercaladas com arenitos.

Segue para leste na bacia do Jacuí, com um alargamento na bacia do rio Taquari-Antas, onde ocupa grande parte da bacia a partir do médio curso, seguindo as áreas ao longo do canal principal. Além disso, forma o alto curso dos rios Sinos, Caí e Gravataí, importantes cursos d'água que abastecem a região metropolitana de Porto Alegre. Nestas áreas, representa a borda do Planalto das Araucárias com topos de rochas vulcânicas ácidas e a base com rochas vulcânicas de básicas intercaladas com arenitos.

Os elementos de relevo do compartimento $\mathrm{F}$ ocorrem no Centro do estado, na bacia do rio Vacacaí e alto curso do rio Camaquã, constituindo o Cinturão Vila Nova, do Escudo Sulrio-grandense composto por granitos e gnaisses associados a rochas metavulcânicas e metassedimentares. Além disso, está representado na porção mais a Norte do Cinturão Tijucas, com predomínio de rochas metamórficas.

\section{Compartimento G- Encostas com base ampla e topos com ressaltos}

O compartimento G caracteriza-se por elementos de relevo definidos, encostas com bases amplas e o topo com elevações alongadas formadas por extensões secundárias e ressaltos.

Este compartimento ocorre no Sudoeste do estado, formando uma faixa de elevações N-S que é o divisor de águas das bacias dos rios Santa Maria e Ibirapuitã, constituindo a passagem do Planalto da Campanha e a Depressão Central.

Ocorre em uma faixa Leste-Oeste junto a margem esquerda do rio Jacuí, que representa uma área de transição entre a Depressão Central e a borda do Planalto das Araucárias, composto por rochas vulcânicas nas cotas superiores das encostas e sedimentares na base.

No Centro-Sul do estado, este compartimento está associado ao Escudo sul-riograndense, compondo a área da Bacia do Camaquã, que é constituída por rochas sedimentares associadas a rochas vulcânicas e vulcanoclásticas, dando origem a um relevo ondulado, associado com morros e morrotes isolados de arenitos conglomeráticos cimentados.

\section{Considerações Finais}

A compartimentação do relevo tem como objetivo estabelecer características quanto à sua configuração e modelado deste, a fim de subsidiar a compreensão de fatores atuantes na sua modelação.

O desenvolvimento cada vez maior de geotecnologias associadas à análise ambiental proporciona a incorporação de procedimentos e técnicas que auxiliem na análise do relevo, através de modelagens e interpretações de modelos digitais de elevação, que auxiliam na compreensão da compartimentação do relevo.

A proposta de identificação dos elementos do relevo, denominados geomorphons, mostrou-se uma técnica bastante eficiente na delimitação de diferentes compartimentos de formas de relevo no estado do Rio Grande do Sul, com distintas e peculiares características que correspondem a unidades reconhecidas geomorfologicamente.

O agrupamento dos elementos de geomorphons em classes predominantes possibilitou a compartimentação do estado do Rio Grande do Sul em sete compartimentos de formas de relevo. O Compartimento de formas de relevo D (Áreas planas com encostas de bases amplas) é o predominante no estado, com $25,95 \%$ da área total, tendo, como elementos de geomorphons predominantes, as áreas planas (flat), seguidos das bases das encostas (footslope).

O segundo maior compartimento de landform do estado é o compartimento A (Encostas com bases Amplas), ocupando $21,52 \%$ da área total, e representa o agrupamento de geomorphons predominantemente associados às encostas (slope) e aos vales (valley). $\mathrm{O}$ compartimento de landform $\mathrm{C}$ (Encostas com vales encaixados) é o que ocupa a menor área, com apenas $3,68 \%$ da área total, e apresenta o agrupamento dos elementos de geomorphons associados, vales (valley), cristas (ridge) e encostas (slope).

\section{Referências Bibliográficas}

CALDAS, J. T. Aspectos geomorfológicos do estado do Rio Grande do Sul. Revista do Instituto Histórico e Geográfico do Rio Grande do Sul. Porto Alegre, 1938. vol. 18 (2): 253-281. 
CARRARO, C. C.; GAMERMANN, N.; EICK, N. C.; BORTOLUZZI, C. A.; JOST, H.; PINTO, J. F. Mapa Geológico do Estado do Rio Grande do Sul. Escala 1:1.000.000. Instituto de Geociências da UFRGS. Porto Alegre. 1974.

CHEBATAROFF, J. Regiones Naturales de Rio Grande del Sur y del Uruguay - Anais da Associação dos Geógrafos Brasileiros, Volume VI, Tomo I (1951- 1952) - São Paulo, Brasil, 1954.

CRÓSTA, A. P; LOURENÇO, F. S. Proposta de Sítio Geológico ou Paleobiológico do Brasil - Astroblema de Cerro do Jarau,

RS. Comissão Brasileira de Sítios Geológicos e Paleobiológicos (SIGEP). 2008.

DRAGUT, L.; BLASCHKE, T. Automated Classification of Landform Elements Using Object-Based Image Analysis. Geomorphology, vol. 81, 2006, pag. 330-344.

HUGGETT, R. J. Soil Landscape Systems: A model of soil genesis. Geoderma, Amsterdan, 1975. vol. 13, p. 1-22.

INSTITUTO BRASILEIRO DE GEOGRAFIAE ESTATÍSTICA (IBGE). Projeto RADAMBRASIL. Levantamento de recursos naturais (Folha SH.22 Porto Alegre e parte das Folhas SH.21 Uruguaiana e SI.22 Lagoa Mirim). Instituto Brasileiro de Geografia e Estatística, Rio de Janeiro, CD-ROM. 1986.

\section{INSTITUTO BRASILEIRO DE GEOGRAFIAE ESTATÍSTICA}

(IBGE). Malhas Digitais. Municípios 2010, Rio de Janeiro,2010. Disponível em <http://downloads.ibge.gov.br/downloads_ geociencias.htm $>$ Acesso junho de 2015 . .

IWAHASHI, J.; PIKE, R. J. Automated Classifications of Topography from DEMs by an Unsupervised Nestedmeans Algorithm and a Three-part Geometric Signature. Geomorphology, 2007. vol. 86. Pag. 409-440.

JASIEWICZ, J.; STEPINSKI, T. F. Geomorphons a Pattern Recognition Approach to Classification and Mapping of Landforms. Geomorphology, 182. 2013. Pag. 147-156

JULESZ, B. Textons, the Elements of Texture Perception, and Their Interactions. Nature, 1981, vol. 290. Pag. 91-97.

JULESZ, B. A Brief Outline of the Texton Theory of Human Vision. Trends in Neuroscience, 1984, vol. 7, pag. 41-45.

LIAO, W. H. Region Description Using Extended Local Ternary Patterns. 20th International Conference on Pattern Recognition, 2010. pag. 1003-1006.

MACMILLAN, R. A.; SHARY, P. A., Landforms and landform elements in geomorphometry. In: HENGL, T. e REUTER, H. I. (eds), Geomorphometry-Concepts, Software, Applications. Developments in Soil Science, Amsterdam Elsevier, 2009. vol.
33. pag. 227-254.

MARTINS, L.C., WILDNER, W.; HARTMANN, L. A. Estratigrafia dos Derrames da Província Vulcânica Paraná na Região Oeste do Rio Grande do Sul, Brasil, com Base em Sondagem, Perfilagem Gamaespectrométrica e Geologia de Campo. Pesquisas em Geociências, 2011. vol 38 (1). pág. 15-27. MOREIRA, A. A. N.; LIMA, G. R. Relevo In: IBGE, Departamento de Geografia, Geografia do Brasil, Região Sul, 1977, v.5, p.1-37.

MÜLLER FILHO, I. L. Notas para o Estudo da Geomorfologia do Rio Grande do Sul. UFSM, Santa Maria, 1970.

MUÑOZ, V. A. Análise Geomorfométrica de Dados SRTM Aplicada ao Estudo das Relações Solo-Relevo. Instituto Nacional de Pesquisas Espaciais, São José dos Campos, 2009. 112p. Dissertação (Mestrado em Sensoriamento Remoto).

NOGUEIRA, P. C. Regiões fisiográficas do Estado do Rio Grande do Sul. Boletim Geográfico, 1948, vol 6 (64). pag. 337-346.

RAMBO B. A fisionomia do Rio Grande do Sul. Porto Alegre: Selbach. 1956

SENA-SOUZA; J; NEVES, G.; VASCONCELOS, V.; MARTINS, E.; JUNIOR, A. Mapeamento das Formas de Terreno por meio de Assinatura Geomorfométrica como Subsídio para a Descrição da Paisagem da Bacia Hidrográfica do Alto Rio Preto. Anais XVII Simpósio Brasileiro de Sensoriamento Remoto SBSR, João Pessoa-PB, Brasil,25 a 29 de abril de 2015, INPE, pag. 1617-1624.

SCHMIDT, J.; HEWITT, A. Fuzzy Land Element Cclassification from DTMs Based on Geometry and Terrain Position. Geoderma, 2004, vol. 121. Pag. 243-256.

SHUTTLE RADAR TOPOGRAPHY MISSION (SRTM). U.S. Releases Enhanced Shuttle Land Elevation Data. Disponível em: $<<$ http://www2.jpl.nasa.gov/srtm/ $>>$. Acesso em fevereiro de 2015 .

TROEH, F. R. Landform Equations Fitted to Contour Maps. American Journal Science, 1965, v. 263, pag. 616-627.

UNITED STATES GEOLOGICAL SURVEY (USGS). USGS Global Visualization Viewer. Disponível em $:<<$ https://lpdaac. usgs.gov/data_access/glovis $>>$. Acesso em fevereiro de 2015.

WILDNER, W; RAMGRAG, G. E.; LOPES R. C.; IGLESIAS, C. M. F. Mapa Geológico do Estado do Rio Grande do Sul. Escala 1:750000. CPRM, Serviço Geológico do Brasil. Porto Alegre, RS. 2006. 
Robaina L. E. S. et al.

WOOD, J. The Geomorphological Characterization of Digital

Elevation Models. Ph.D. Thesis, Department of Geography, University of Leicester, UK, 1996.

VASCONCELOS, V.; JÚNIOR, O.; MARTINS, E.; JUNIOR,
A.; GUIMARÃES, R.; GOMES, R. Sistema de Classificação Geomorfométrica Baseado em uma Arquitetura Sequencial em duas Etapas: Árvore de Decisão e Classificador Espectral, no Parque Nacional Serrada Canastra. Revista Brasileira de Geomorfologia, 2012. v. 13, nº 2, pág.171-186. 